\title{
Immediate Effect of Strain/ Counterstrain V/S Myofascial Release on Local Pain of Upper Trapezitis
}

\author{
Priya Gupta ${ }^{1 *}$ and Nehal Shah ${ }^{2}$ \\ ${ }^{1}$ MPT (Sports), Team Physiotherapist Gujarat Cricket Association, India \\ ${ }^{2}$ Professor, Phd, Principal, S.B.B. College of Physiotherapy, Ahmedabad, Gujarat, India \\ *Corresponding Author: Priya Gupta, MPT (Sports), Team Physiotherapist Gujarat \\ Cricket Association, India.
}

Received: June 13, 2019

Published: March 182020

C) All rights are reserved by Priya Gupta and Nehal Shah.

\begin{abstract}
Study Design: Quasi Experimental study.

Objective: The aim of this study is to compare the immediate effect, on pain, following a single treatment of tender points in the upper trapezius muscle involving the strain/counterstrain technique and myofascial release.

Method: Thirty subjects presenting with trapezitis, aged 18 - 25 years old, were selected for this study. Subjects were divided into 2 groups, group A which was treated with the strain/counterstrain technique and group B which was treated with the myofascial release technique. The outcome measure was the visual analogue scale assessing local pain elicited by the application of pressure on the tender point. It was assessed pre-treatment and 2 min post- treatment by an assessor blinded to the treatment allocation of the subject.

Results: Results of between group analysis showed positive findings concluding that Strain/counter strain technique was nearly $10 \%$ more effective in reducing pain on VAS than Myofascial release $(\mathrm{p}=0.016)$.

Conclusion: In this study it was found that SCS was more effective than MFR in immediate pain relief of active TrP of upper trapezius.
\end{abstract}

Keywords: Strain/Counterstrain; Myofascial Release; Visual Analogue Scale; Upper Trapezitis

\section{Introduction}

Trapezitis

Trapezius pain is the classic stress pain and it is the most common musculoskeletal disorder. It is usually caused by placing too much stress or strain over the trapezius muscle. The trapezius musculature is an inverted triangle which starts at the base of the skull, spreads over the shoulders and down to the mid back. The upper trapezius muscles are designated as postural muscle and it is highly susceptible to overuse. Trapezius muscles help with the function of neck rotation, side bending and extension. Tightness in the muscles can decrease the range of motion of the neck. The decrease in motion can negatively affect the mobility of the cervical joints. Limited range of motion creates an increase in soft tissue tightness, with an ensuing pain-spasm cycle which can be difficult to break.

\section{Trigger points}

Overloading and injury of muscle tissue lead to involuntary shortening of localized fibers. The areas of stressed soft tissue receive less oxygen, glucose, and nutrient delivery, and subsequently accumulate high levels of metabolic waste products. The end result of this cascade of events is the creation of altered tissue status, pain, and the development of Trigger points (TrP) (Figure 1).

\section{Strain/counterstrain technique}

SCS has also been utilized in the manual treatment of TrPs. This approach involves identification of the active TrPs, followed by the application of pressure until a nociceptive response is produced. The area is then positioned in such a manner as to reduce the tension in the affected muscle and subsequently the pain in the TrP. When the position of ease/pain reduction is attained, the stressed 
tissues are felt to be at their most relaxed and a local reduction of tone is produced.

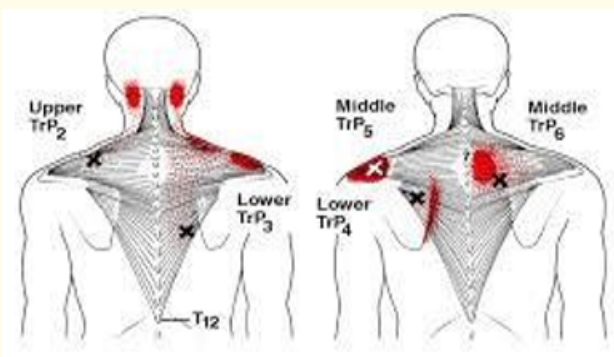

Figure 1

\section{Myofascial release technique}

Myofascial Release is an effective hands-on therapy which can directly change and improve health of the fascia. The purpose of Myofascial Release is to break down scar tissue, relax the muscle and myofascia and restore good posture. Myofascial Release techniques focus on relaxing the deep tissue of the body providing lasting and effective relief to the client and patient. As mentioned, Myofascial Release technique is applied directly on the body and uses slow and sometimes deep pressure to restore the proper health of the fascia.

Need of the study: SCS and MFR are two commonly used techniques which relieve pain. Not many studies have been done to see which of the two is better. Hence this study was conducted with the intent to compare the immediate effects of the two on local pain and find out if there is any significant difference in their effect on pain.

\section{Methodology}

A Quasi experimental study was conducted at the S.B.B. College of Physiotherapy. 30 patients (aged 18 - 25 years) with nonspecific neck pain were recruited for this study. The nature of the study was explained to the patients and a written consent form was taken from them. These patients were randomly divided into 2 groups: Group A and Group B. Group A was treated with the strain/counter strain technique and group $B$ was treated with the myofascial release technique. The outcome measure was the visual analogue scale assessing local pain elicited by the application of pressure on the tender point. It was assessed pre-treatment and 2 min posttreatment by an assessor.

\section{Inclusion criteria}

- $\quad$ A palpable tender spot in the upper trapezius muscle.

- Reproduction of subject's pain on palpation.

- A jump sign characterized by patient's vocalization or withdrawal.

- $\quad$ Participants willing to participate.

\section{Exclusion criteria}

- Referred pain due to cervical pathology.

- Individuals with healing fractures over neck and upper back region.

- $\quad$ Dermatitis over upper back.

- Referred pain due to cervical pathology.

- Individuals with healing fractures over neck and upper back region.

- Dermatitis over upper back.

- $\quad$ Patients with wound over neck region

- If they had received trigger point injections in the upper trapezius muscle within the past 6 months.

\section{Strain/counterstrain technique}

In this technique the patient is in supine position and the patients head is side flexed to the side being treated and the arm is elevated in abduction and external rotation (above $90^{\circ}$ ) and the position is held for 90 seconds. This position was given once.

\section{Myofascial release technique}

In this technique the patient is in sitting with forward lean position. One hand keeps pressure on the origin of the muscle stabilizing it while the other hand is dragged to the insertion with pressure thus releasing the myofascia of the upper trapezius. This technique was given thrice.

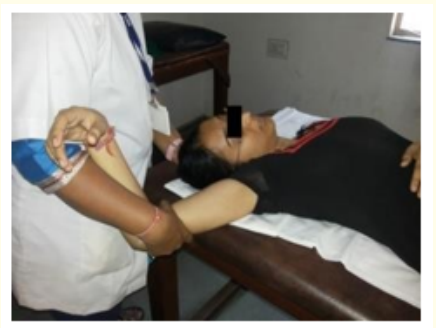

Figure 2: Strain/counter strain technique. 


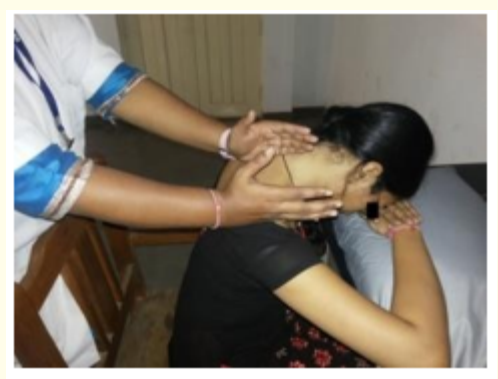

Figure 3: Myofascial release technique.

\section{Outcome measure}

VAS was used as an outcome measure. VAS is a self-assessing tool. It is an ordinal scale, using a $10 \mathrm{~cm}$ line with 0 representing "no pain" and 10 representing "unbearable pain". Each participant was asked to indicate on the scale the level of his/her pain before and after treatment. The patient would be marking on the scale himself indicating as a subjective experience. Hence, the VAS scale has high reliability and validity [1].

\section{Results}

Statistical analysis was done using SPSS 16.0. Variables were evaluated to ensure that they were normally distributed using histogram with normal curve. The data was parametric in nature. The level of significance was set $5 \%$.

\begin{tabular}{|l|l|l|l|}
\hline $\begin{array}{l}\text { Outcome } \\
\text { measure }\end{array}$ & $\begin{array}{l}\text { Test used to } \\
\text { compare } \\
\text { within Group A }\end{array}$ & $\begin{array}{l}\text { Test used } \\
\text { to compare } \\
\text { within } \\
\text { Group B }\end{array}$ & $\begin{array}{l}\text { Test used to } \\
\text { compare } \\
\text { between Group } \\
\text { A and B }\end{array}$ \\
\hline VAS & Paired ' $t$ ' test & Paired ' $t$ ' test & Unpaired ' $t$ ' test \\
\hline
\end{tabular}

Table1: Tests used to compare outcome measure within and between groups.

\begin{tabular}{|l|l|l|l|}
\hline Group & No. of patients & Mean age & Standard deviation \\
\hline Group A & 15 & 20.6 & 1.18 \\
\hline Group B & 15 & 22.4 & 1.68 \\
\hline
\end{tabular}

Table 2: Age Distribution.

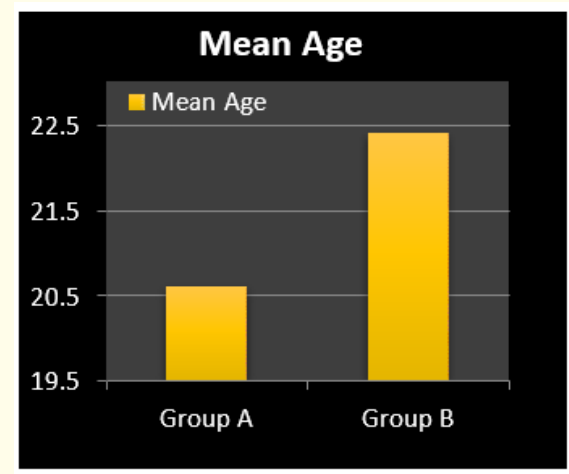

Graph 1: Age Distribution.

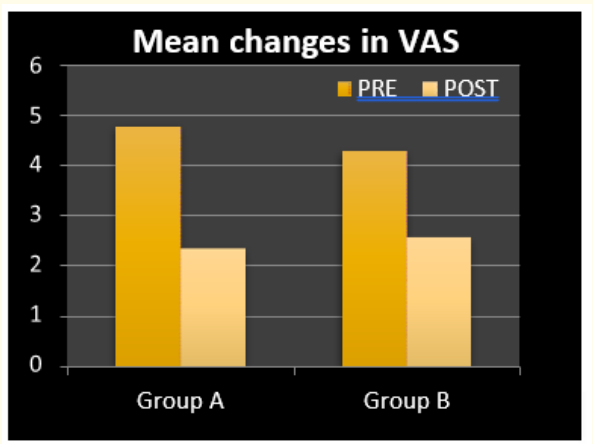

Graph 2: Mean changes in Visual Analogue Scale in Group A and B.

Within the groups, paired t-test was performed for analysis in group A and B. For group A, P $<0.01$ was found to be significant $[3,4]$. For group $B, P<0.01$ was found to be significant [2].

\begin{tabular}{|l|l|l|l|l|}
\hline Groups & Pre-treatment & Post-treatment & t value & P value \\
\hline Group A & $4.77 \pm 1.58$ & $2.33 \pm 1.58$ & 10.15 & $<0.01$ \\
\hline Group B & $4.27 \pm 1.23$ & $2.54 \pm 1.13$ & 12.46 & $<0.01$ \\
\hline
\end{tabular}

Table 3: Mean changes in Visual Analogue Scale within Group A and B. 


\section{Group A versus group B}

Unpaired t test was performed for analysis, VAS between the group was found to be significant with $\mathrm{p}=0.016$. The results show that there was significant improvement in VAS scale in group A (treated with strain/counter strain technique) compared to group B (treated with myofascial release).

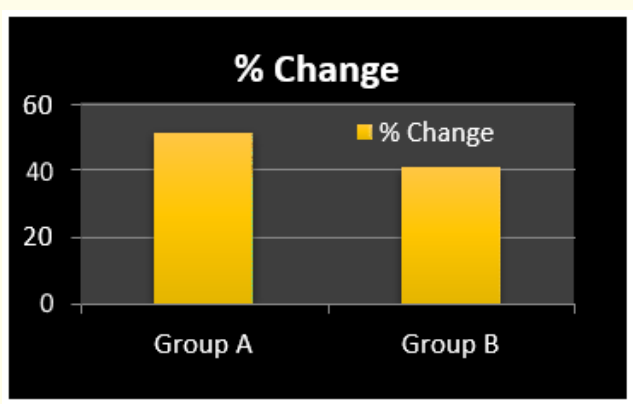

Graph 3: \% changes in VAS between Groups A and B.

\section{Discussion}

This study was done to compare the immediate effect of strain/ counterstrain technique and myofascial relief on pain with upper trapezitis. This study recruited subjects with active TrP in upper trapezius muscle as it is most frequently affected and commonly cited in clinical settings. The subjects were suffering from pain even at rest. The result of the present study, showed positive findings for within group analysis indicating that group A receiving Strain/counter strain technique and group B receiving Myofascial release both had significant improvement in pain $(p<0.01)$.

During the strain/counter strain technique, the involved tissue is "slackened" causing a relaxation of the "spasm" which, in turn, allows local areas of inflammation, trapped within the painful tissue to dissipate. Following this "release" there is an immediate reduction of pain and tension in the involved tissue. In accordance with this in June 2006 Caser Fernandez-de-las-Penas., et al. studied the immediate effect of strain/counter strain technique in local pain evoked by tender points in the trapezius muscle and found this technique is effective in reducing tenderness of tender points [4].

The myofascial release method engages the myofascial tissue "restrictive barrier" (tension). The tissue is loaded with a constant force until release occurs. Practitioners use knuckles or elbows. In October 2002 Hou CR., et al. studied immediate effects of various physical therapeutic modalities on cervical myofascial pain and trigger-point sensitivity. They suggest that therapeutic combinations such as hot pack plus active ROM and stretch with spray, hot pack plus active ROM and stretch with spray as well as TENS, and hot pack plus active ROM and interferential current as well as myo- fascial release technique, are most effective for easing MTrP pain and increasing cervical ROM [2].

Results of between group analysis also showed positive findings concluding that Strain/counter strain technique was nearly $10 \%$ more effective in reducing pain on VAS than Myofascial release ( $p$ $=0.016$ ). The present study resulted in a considerable decrease in pain in group A where Strain/counter strain was given.

\section{Conclusion}

In patients with non-specific neck pain SCS and MFR were both found to be effective in immediate pain relief. VAS between the groups was found to be significant. The results show that there was significant improvement in VAS scale in group A (treated with strain/counterstrain technique) compared to group B (treated with myofascial release).In this study it was found that SCS was more effective than MFR in immediate pain relief of active TrP of upper trapezius.

\section{Limitations and Further Studies}

Limitations of this study are: small sample size, blinding is not done and the long term effects not considered. Hence further studies need to be done to compare the long term effects of these two therapies on pain.

\section{Bibliography}

1. Polly E Bijur., et al. "Reliability of Visual Analogue Scale for measurement of acute pain". Academic Emergency Medicine 8.12 (2001): 1153-1157.

2. Hou CR., et al. "Immediate effects of various physical therapeutic modalities on cervical myofascial pain and trigger-point sensitivity". Archives of Physical Medicine and Rehabilitation 83.10 (2002): 1406-1414.

3. Sirikam Somprasong., et al. "Effects of strain/counter strain and stretching techniques in active myofascial pain syndrome". Journal of Physical Therapy Science 23.6 (2011): 889-893.

4. Albert Atienza Meseguer., et al. "Immediate effects of the strain/counterstrain technique in local pain evoked by tender points in the upper trapezius muscle". Clinical Chiropractic 9.3 (2006): 112-118.

\section{Assets from publication with us}

- Prompt Acknowledgement after receiving the article

- Thorough Double blinded peer review

- Rapid Publication

- Issue of Publication Certificate

- High visibility of your Published work

Website: www.actascientific.com/

Submit Article: www.actascientific.com/submission.php Email us: editor@actascientific.com

Contact us: +919182824667 